\title{
Non-stationary flow of hydraulic oil in long pipe
}

\author{
Lumír Hružík $^{1, \mathrm{a}}$, Adam Bureček ${ }^{1}$, and Martin Vašina ${ }^{1}$ \\ ${ }^{1}$ VŠB - Technical University of Ostrava, Faculty of Mechanical Engineering, Department of Hydromechanics and \\ Hydraulic Equipment, 70833 Ostrava, Czech Republic
}

\begin{abstract}
The paper deals with experimental evaluation and numerical simulation of non-stationary flow of hydraulic oil in a long hydraulic line. Non-stationary flow is caused by a quick closing of valves at the beginning and the end of the pipe. Time dependence of pressure is measured by means of pressure sensors at the beginning and the end of the pipe. A mathematical model of a given circuit is created using Matlab SimHydraulics software. The long line is simulated by means of segmented pipe. The simulation is verified by experiment.
\end{abstract}

\section{Introduction}

Non-stationary flow is characterized by changes of characteristic flow quantities (e.g. pressure and velocity) not only with position, but also with time. A high pressure increasing (e.g. as a result of a hydraulic shock) can be achieved at very rapid flow velocity changes. It is necessary to consider liquid compressibility and elasticity of hydraulic lines (i.e. pipes and hoses). The abovementioned aspects have a big influence on dynamic properties of hydraulic systems.

Hydraulic shock can be defined as non-stationary flow of compressible liquid. This flow is characterized by flow and pressure changes. A creation of the hydraulic shock is due to a change of initial velocity of liquid flow [1]. Positive or negative liquid acceleration in a given pipe point can by caused by valve closure or by failure. The shock is manifested by periodic pressure pulsations that are propagated to pipe walls [2]. The pulsations can conduce to deformation or destruction of the pipe. There are realized suitable arrangements in order to eliminate this danger, e.g. by means of hydraulic accumulator or by slower valve closure. The hydraulic shock can also conduce to liquid column separation and subsequent underpressure in this point. As a result, air and steam bubbles are released in the liquid [3].

The Matlab SimHydraulics [4] software was used to mathematical simulation of the hydraulic shock. The software makes it possible physical access to simulation. The simulation model consists of hydraulic elements in this case. The elements are described by mathematical equations and are at disposal in elements library. Segmented pipe with concentric parameters was used to simulation of dynamic behaviour of the system with long pipe. The numerical model was verified on real experimental equipment.

\section{Description of experimental equipment and measurement}

The experimental equipment makes it possible to realize dynamic processes of a hydraulic system with long pipe.

The schematic diagram of the equipment is shown in figure 1. The hydraulic pump HP is a pressure liquid source. The hydraulic aggregate also consists of the check valve $\mathrm{CV}$, relief valve $\mathrm{RV}$ and the tank T. Mineral oil with the temperature $t_{o}=26^{\circ} \mathrm{C}$ is used as the working liquid in this case. The proportional valve $\mathrm{PV}$ is used to flow control. The hydraulic system also consists of the long steel pipe PIPELINE, which is stepped with the seat valves SV1 and SV2 at its beginning and at its end. The flow sensor FS is located on the output line between the seat valve SV2 and the tank T. The pressure sensors PS1 and PS2 are connected to the pipeline (see figure 1) between the valves SV1 and SV2 [5].

The parameters of the experimental equipment are the following:

1. Hydraulic oil - density $\rho=865 \mathrm{~kg} \cdot \mathrm{m}^{-3}$, kinematic viscosity $v=87.5 \mathrm{~mm}^{2} \cdot \mathrm{s}^{-1}$, bulk modulus $K_{O}=1.59 \cdot 10^{9} \mathrm{~Pa}$, air content $\alpha=0.5 \%$.

2. PIPELINE - length $l=60 \mathrm{~m}$, outside diameter $D=0.016 \mathrm{~m}$, inside diameter $d=0.012 \mathrm{~m}$, material - steel, Young modulus of elasticity $E_{P}=2.1 \cdot 10^{11} \mathrm{~Pa}$, Poisson ratio $v_{P}=0.3$, static pressure-diameter coefficient $K_{P}=2.2 \cdot 10^{-13}$ $\mathrm{m} \cdot \mathrm{Pa}^{-1}$ - see the following equation [4]:

\footnotetext{
${ }^{\mathrm{a}}$ Corresponding author: lumir.hruzik@vsb.cz
} 


$$
K_{P}=\frac{d}{E_{P}} \cdot\left(\frac{D^{2}+d^{2}}{D^{2}-d^{2}}+v_{P}\right)
$$

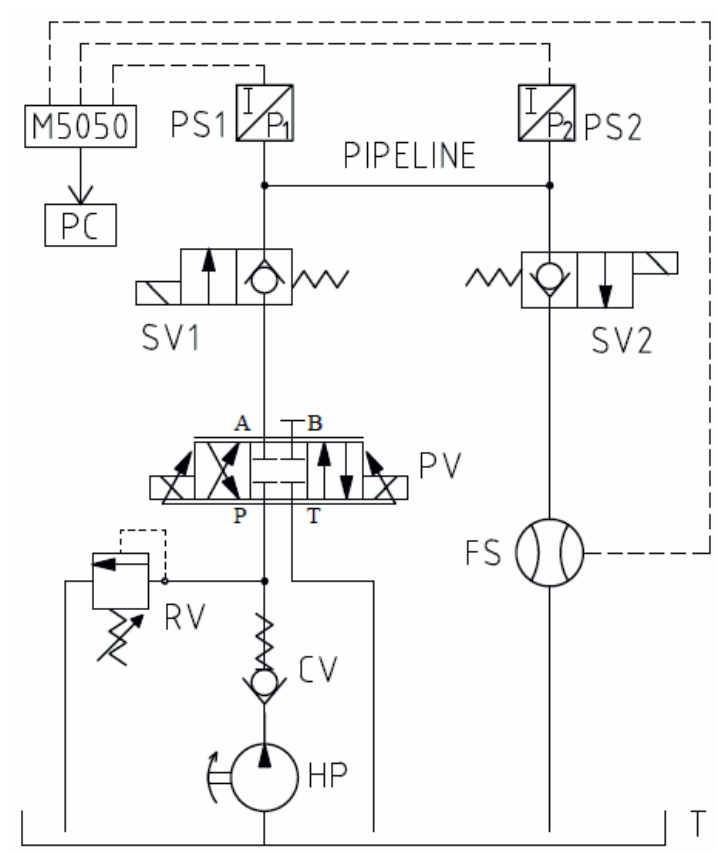

Figure 1. Scheme of experimental equipment.

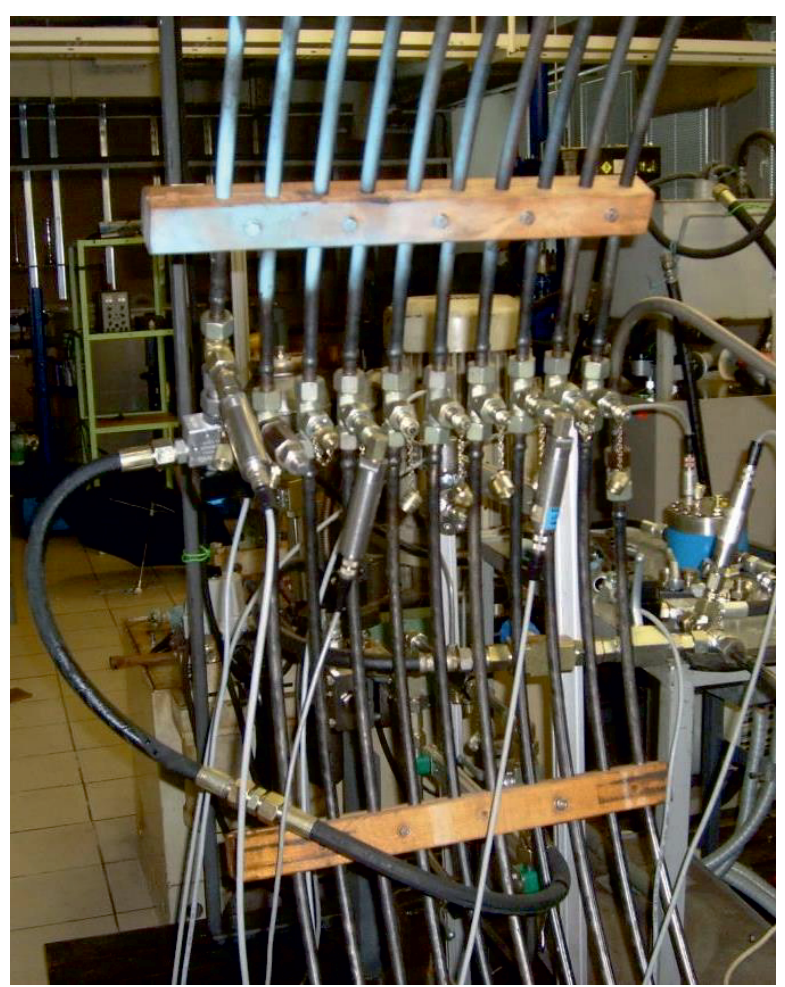

Figure 2. View of experimental circuit.

The measurement was performed in the following way: The pressure $p=50$ bar is adjusted at input of the proportional valve $\mathrm{PV}$. The flow $Q=22 \mathrm{dm}^{3} \cdot \mathrm{min}^{-1}$ is adjusted on the proportional valve PV. Hydraulic oil flows through a long pipe. The seat valves SV1 and SV2 are suddenly closed at the same time. Consequently, there is the hydraulic shock in the pipe. The pressures $p_{1}$ and $p_{2}$ are evaluated by the pressure sensors PS1 and PS2 of
PR15 Hydrotechnik type with the measuring range of $(0 \div 400)$ bar and the $\pm 0.5 \%$ accuracy. Signals from the pressure sensors are recorded by means of measuring equipment type Hydrotechnik M5050 [6]. The measured data are evaluated using Hydrowin software and subsequently compared with a numerical model.

The time dependencies of the pressures $p_{1}$ (i.e. at the pipe input) and $p_{2}$ (i.e. at the pipe output) are shown in figure 3. It is evident that the pressures $p_{1}$ and $p_{2}$ oscillate with the same frequency. The pressure amplitudes are subsequently damped. There is a phase displacement of the pressures by half of the period in this case.

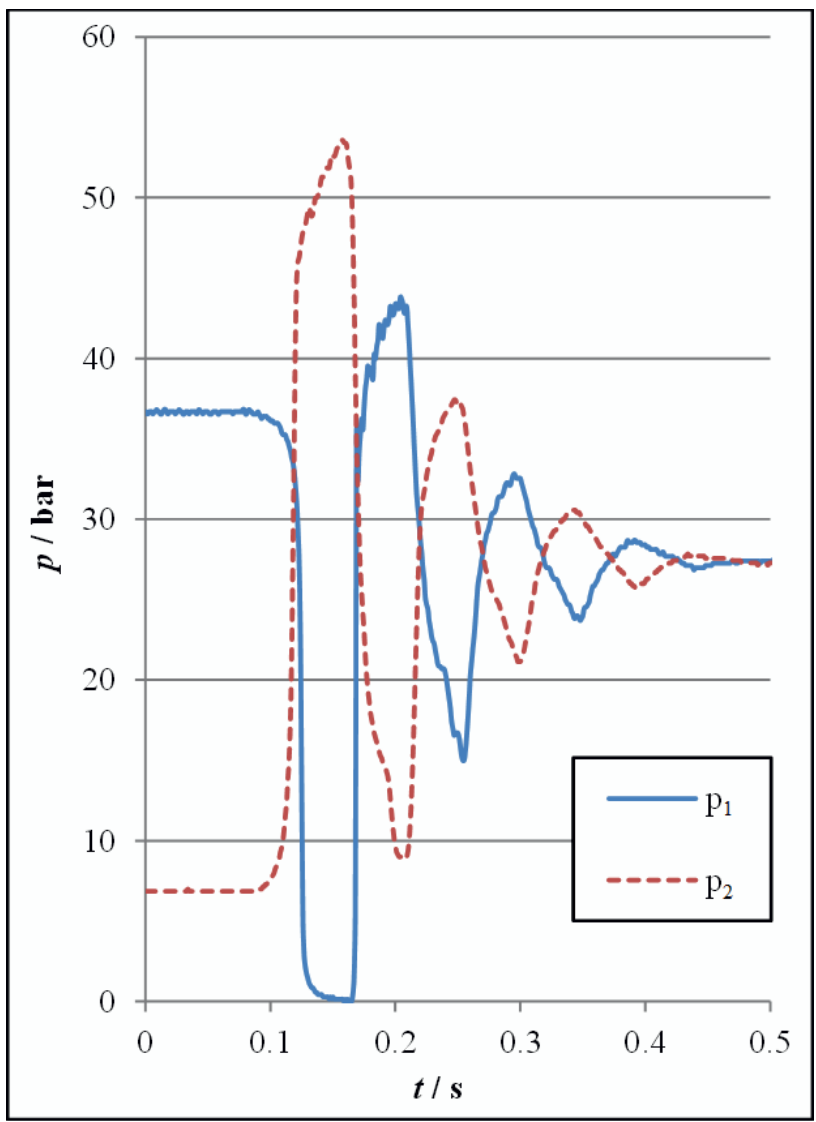

Figure 3. Measured time dependencies of pressures $p_{1}$ and $p_{2}$ (Hydrowin software).

\section{Description of mathematical model}

The numerical model was created using Matlab SimHydraulics software (see figure 4) [1,7]. Dynamic properties of the hydraulic system were evaluated for a step closing of the seat valves SV1 and SV2 at the input and the output of the pipe. There are created subsystems from less interesting blocks for the mathematical model in this case. For example, the subsystem Control of SV1 and SV2 is shown in figure 12 .

The hydraulic pump HP with the pressure $p=50$ bar is a pressure liquid source of the system. Oil flows through the check valve CV and the seat valve SV1 into the pipe PIPELINE. Furthermore, it flows through the seat valve SV2 and the flow sensor FS back to the tank T. The relief valve is used to system overload protection. 
The model also consists of the blocks Control of SV1 and SV2 (i.e. for control of seat valves), the blocks PS1 and PS2 for pressure measurements, the block FS for flow measurement and the block Solver Configuration. The scanning time interval $\Delta t=0.001 \mathrm{~s}$ was adjusted by the block Time similarly as in the case of experimental measurements. The block Custom Hydraulic Fluid was used in order to adjustment of oil parameters. The value of undissolved air content in oil was $\alpha \cong 0.5 \%$. The long pipe PIPELINE is simulated as a segmented pipe with concentric parameters [8].

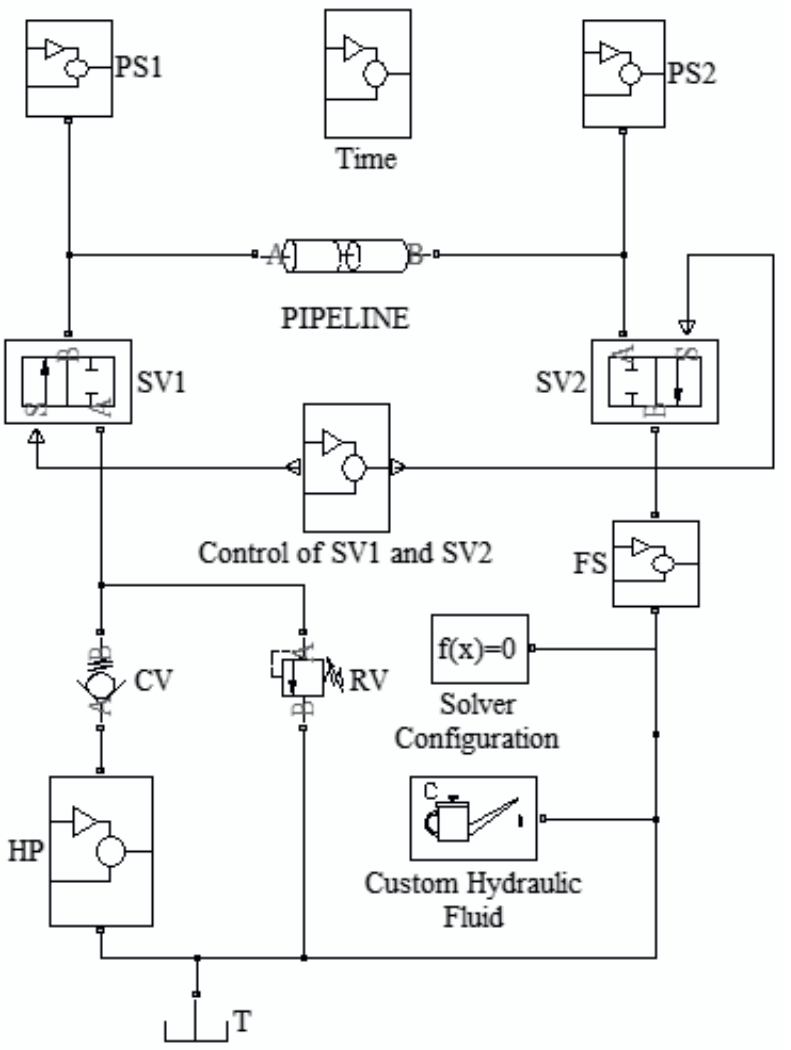

Figure 4. Mathematical model of experimental equipment.

Segmented Pipeline of circular cross-section (see figure 5) is divided by longitudinal sections into a set of identical serially arranged parts - concentric parameters. Each part consists of Resistive Tube (i.e. resistance to motion), Fluid Inertia (i.e. resistance to acceleration) and Constant Volume Hydraulic Chamber (i.e. resistance to deformation). In the case of one segment, it is assumed a symmetric T-part. Every other segment is considered as L-part [4].

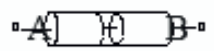

Figure 5. Block of segmented pipe.

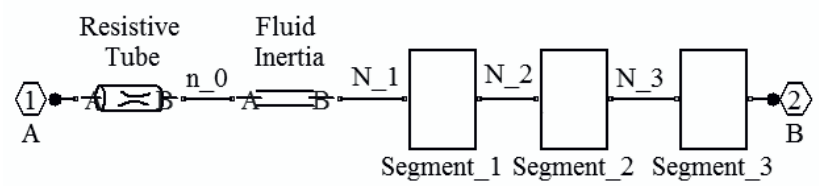

Figure 6. Composition of segmented pipe.

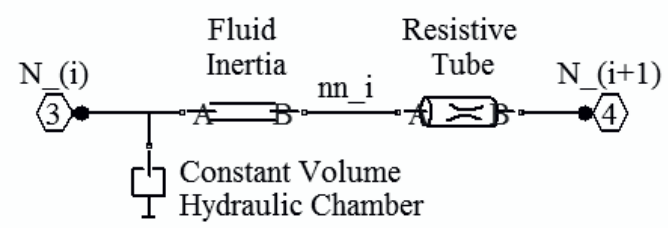

Figure 7. Composition of one segment.

\section{Comparison of experimental measurement and simulation}

\subsection{Current closing of valves}

The mathematical simulation of a step closing of the seat valves SV1 and SV2 was performed first of all. It conduces to the hydraulic shock and pressure oscillations. The time dependencies of the measured and simulated pressures are shown in figures 8 and 9 .

The numerically simulated pressure dependence corresponds with the experimental measurement, namely in terms of the period of oscillation and the pressure amplitude. In this case, the system eigenfrequency is $f=10 \mathrm{~Hz}$.

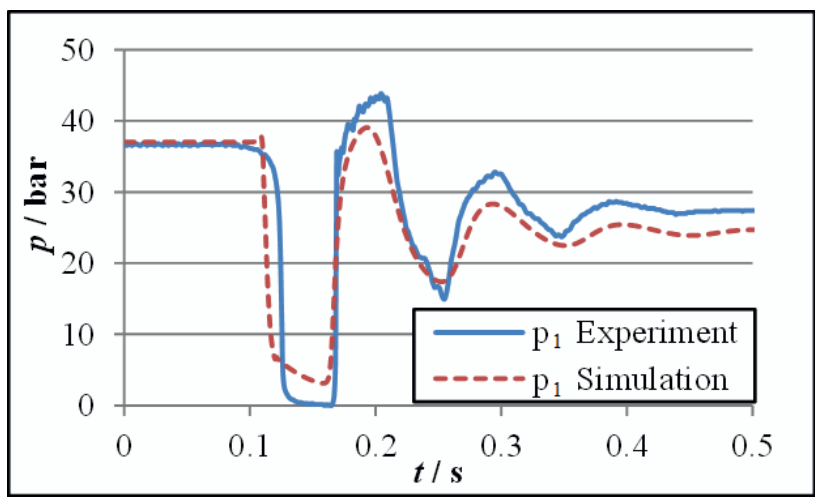

Figure 8. Time dependencies of pressure $p_{1}$ at step closing of valves SV1 and SV2.

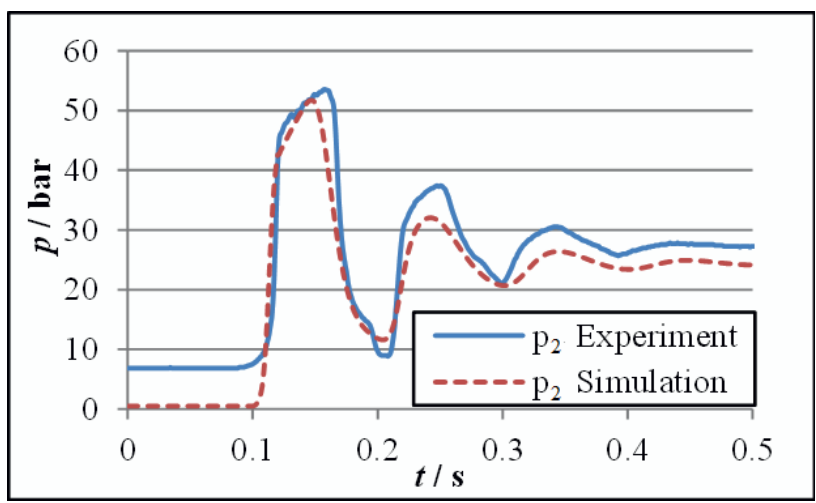

Figure 9. Time dependencies of pressure $p_{2}$ at step closing of valves SV1 and SV2.

It is evident that pressure pulsations are gradually damped by reason of friction which depends on liquid viscosity and pipe wall roughness. The system eigenfrequency depends mainly on pipe length, boundary conditions, oil bulk modulus and undissolved air content in liquid. 


\subsection{Valve closure at pipe output}

The mathematical simulation was subsequently performed for a step closing of the seat valve SV2. The simulated and measured time dependencies of the pressure $p_{2}$ are shown in figure 10 .

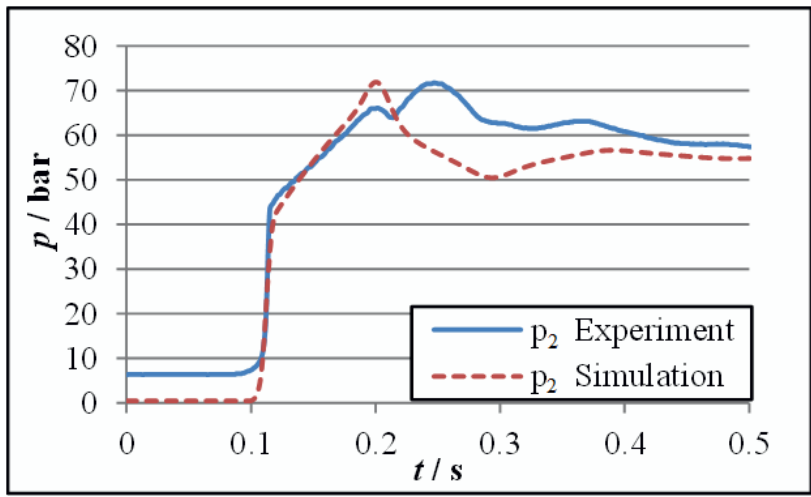

Figure 10. Time dependencies of pressure $p_{2}$ at step closing of valve SV2.

The liquid pressure at the output pipe at closing of the seat valve SV2 was increased to the value $p_{2}=72$ bar. The pressure is subsequently decreased (after the lapse of the time $t_{k}=0.6 \mathrm{~s}$ ) to the value, which is adjusted by the relief valve RV. The pressure peak size depends on liquid flow velocity before the valve closure and on velocity of valve closure.

\subsection{Valve closure at pipe input}

The mathematical simulation was subsequently performed for a step closing of the seat valve SV1. The simulated and measured time dependencies of the pressure $p_{2}$ are shown in figure 11. It is evident that the measured and simulated dependencies are very similar.

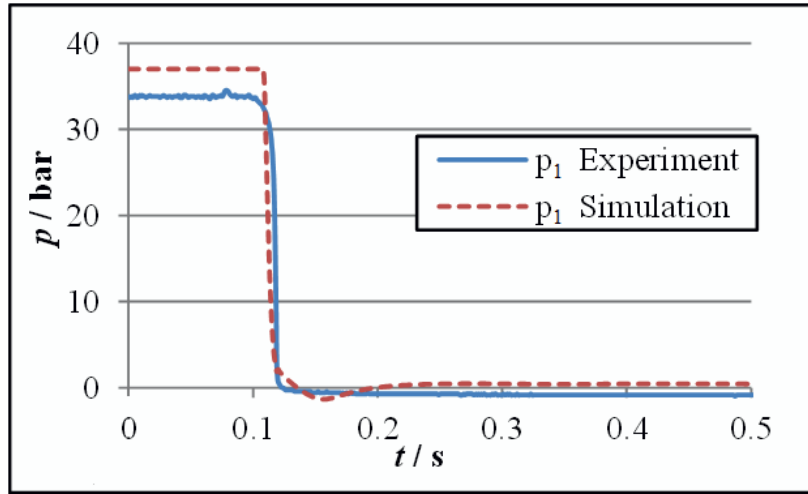

Figure 11. Time dependencies of pressure $p_{1}$ at step closing of valve SV1.

\section{Influence of valve closing time}

As mentioned above, the hydraulic shock can be partly eliminated, e.g. by slower closing of valves. It is realized by the subsystem Control of SV1 and SV2 (see figure 12) in the mathematical model, in the concrete by the block Proportional and Servo-Valve Actuator. This block was used to an adjustment of the closing time of the seat valves SV1 and SV2 and the ramp function in compliance with figure 13 .

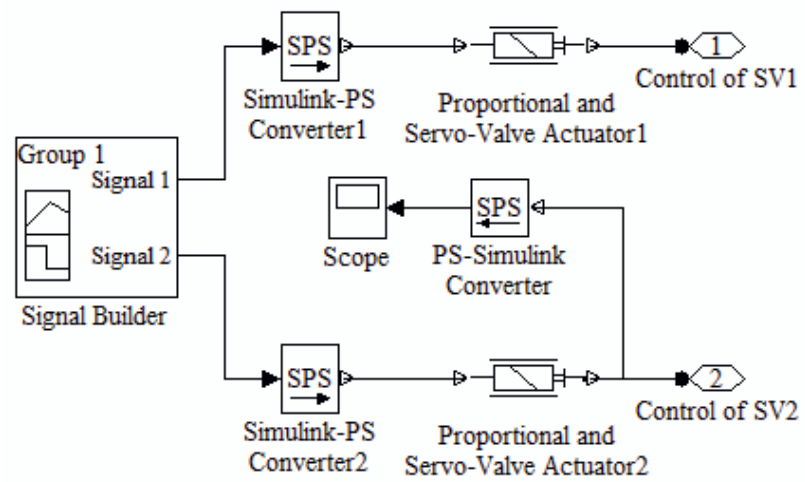

Figure 12. Schematic diagram of subsystem Control of SV1 and SV2.

The original closing time $t_{R 1}=20 \mathrm{~ms}$ of the seat valves was increased to the value $t_{R 2}=250 \mathrm{~ms}$ (see figure 13). The regulation parameter $\varphi=1$ comports with the fully open valve.

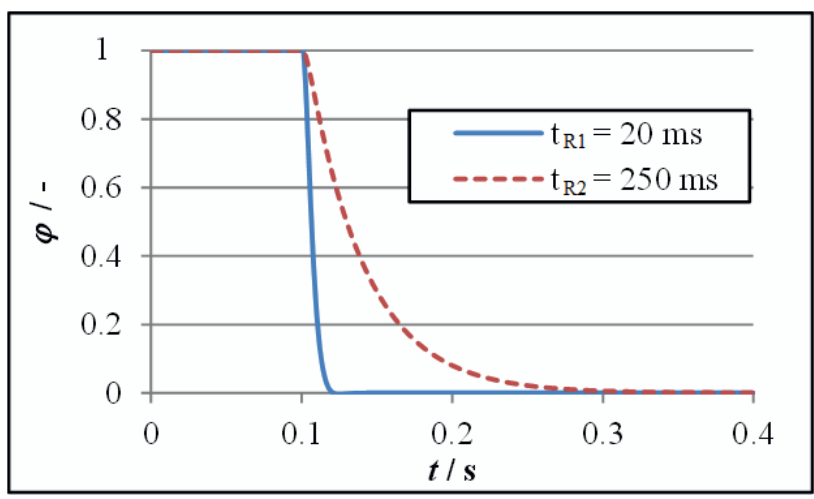

Figure 13. Ramp functions $t_{R 1}=20 \mathrm{~ms}$ and $t_{R 2}=250 \mathrm{~ms}$ at closing of seat valve.

The mathematical simulation was subsequently performed for a step closing of the seat valves SV1 and SV2 with a longer ramp $t_{R 2}$. The time dependencies of the pressures $p_{1}$ and $p_{2}$ are shown in figures 14 and 15 .

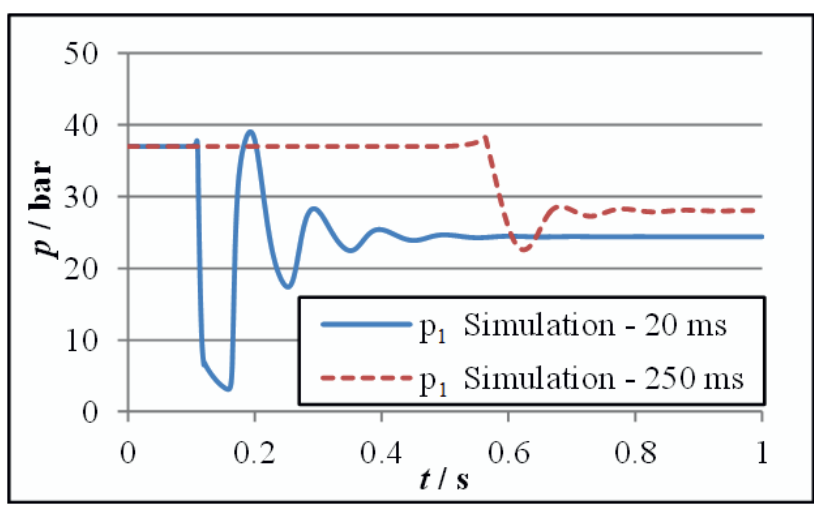

Figure 14. Comparison of time dependencies of pressure $p_{1}$ at step closing of valves SV1 and SV2 for ramps $t_{R 1}=20 \mathrm{~ms}$ and $t_{R 2}=250 \mathrm{~ms}$.

Before closing of the seat valves SV1 and SV2, the working liquid flows through the pipe with the pressure $\operatorname{loss} p_{1}=37$ bar (see figures 14 and 15). 


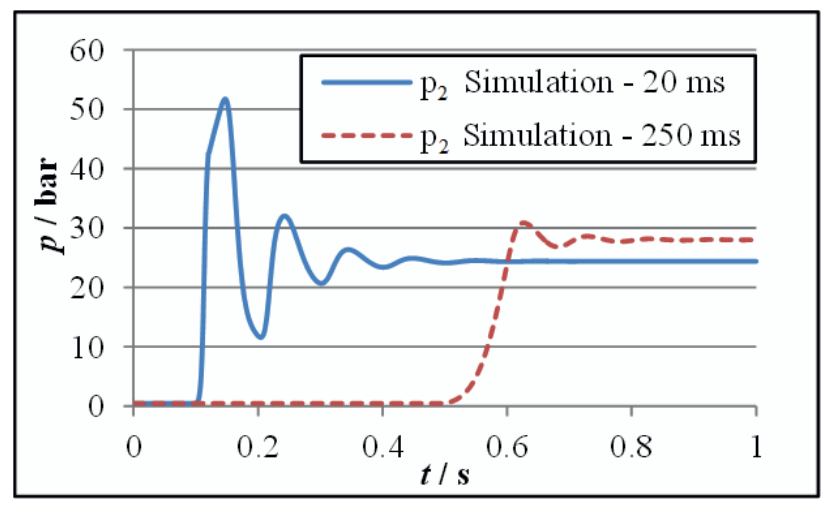

Figure 15. Comparison of time dependencies of pressure $p_{2}$ at step closing of valves SV1 and SV2 for ramps $t_{R 1}=20 \mathrm{~ms}$ and $t_{R 2}=250 \mathrm{~ms}$.

The pressure at the pipe output is increased to the value $p_{2}=52$ bar by reason of the rapid closing (i.e. $t_{R 1}=20 \mathrm{~ms}$ ) of the valves SV1 and SV2. The overshooting $\Delta p_{2}$ in comparison with the steady-state value of the pressure $p_{2}$ is in this case $\Delta p_{2}=28$ bar (see figure 15). In the case of the slow closing (i.e. $t_{R 2}=250 \mathrm{~ms}$ ) of the valves, the overshooting is smaller (i.e. $\Delta p_{2}=2$ bar) in comparison with the steadystate value. It is a markedly lower value of the overshooting in comparison with the rapid closing of the valves. It is evident that the hydraulic shock was strongly eliminated by the slow closing of the valves.

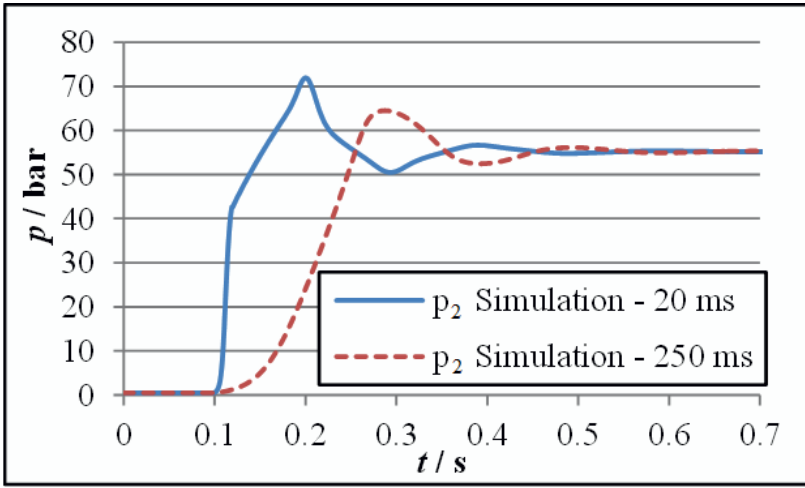

Figure 16. Comparison of time dependencies of pressure $p_{2}$ at step closing of valve SV2 for ramps $t_{R 1}=20 \mathrm{~ms}$ and $t_{R 2}=250 \mathrm{~ms}$.

The simulated dependencies of the pressure $p_{2}$ at closing of the seat valve SV2 (i.e. $t_{R 1}=20 \mathrm{~ms}$ ) and for the rapid closing of the valve SV2 (i.e. $t_{R 2}=250 \mathrm{~ms}$ ) is shown in figure 16. It is visible that the slow closing has a positive influence on elimination of the hydraulic shock.

\section{Conclusions}

The experimental equipment with long pipe for realization of dynamic processes was described in this paper (see figure 1). The mathematical model of the equipment was obtained using Matlab SimHydraulics software (see figure 4). It was verified by a comparison of the simulation and the experiment on the basis of time dependencies of pressures at step closing of the seat valves SV1 and SV2 at the input and the output of the investigated pipe (see figures 8 and 9). The simulated pressures were subsequently compared (see figures 10 and 11) with the experimental measurements at only one valve closure (i.e. SV2 or SV1). The influence of closing time of the valves SV1 and SV2 was simulated too (see figures 14, 15 and 16). It was found that the hydraulic shock is strongly eliminated by slow closing of the seat valves.

\section{References}

1. M. Kozubková, Matematické modely kavitace a hydraulického rázu (VŠB - TU Ostrava, Ostrava, 2009)

2. D. Himr, EPJ Web of Conferences, EFM12, Numerical Simulation of Water Hammer in Low Pressurized Pipe: Comparsion of SimHydraulics and Lax-Wendroff Method with Experiment, 45, 4 (2013)

3. J. Jablonská, EPJ Web of Conferences, EFM12, Modelling on cavitation in a diffuser with vortex generator, 45, 6 (2013)

4. The MathWorks, Matlab Simulink User's Guide, SimHydraulics User's Guide (USA, 2007)

5. Mannesmann Rexroth, Der Hydraulik Trainer, Band 2, Proportional und Servoventil Technik (Germany, Lohr am Main, 1986)

6. Hydrotechnik GmbH, (catalog sheets)

7. K. Bittner, Simhydraulics - Modelování hydraulických systémů v programu Simulink, http://www.automatizace.cz/article.php?a=1228

8. A. Bureček, L. Hružík, Journal of applied science in the termomechanics and fluid mechanics, Simulation of Hydraulic Circuit with Linear Hydraulic Motor with Mass Load and Dynamic Characteristics, 5, 6 (2011)

\section{Acknowledgements}

This paper has been elaborated in the framework of the project Opportunity for young researchers, reg. no. CZ.1.07/2.3.00/30.0016, supported by Operational Programme Education for Competitiveness and cofinanced by the European Social Fund and the state budget of the Czech Republic. 